\title{
ÉTICA E INVERSIÓN EXTRANJERA ${ }^{1}$
}

\author{
JORGE PINZÓN SÁNCHEZ
}

This paper proposes to use human rights as a reference point with which to measure the behavior of foreign investors. When choosing between the ethical standards of the home and host countries, the paper suggests that investors should favor the most stringent standards, and should evaluate the differences from the perspective of human rights. Ethical judgements in entrepreneurial activity are both possible and relevant, and they motivate economic agents. In fact, free enterprise combines with the ethical expectations of the communities where it exists, and such expectations allow human beings, as ethically responsible subjects, to gauge their conduct. In practice, it is difficult for a country like Colombia to have the moral authority to criticize foreign investors, given the practices of business people, unions, consumers, and other members of society. Nevertheless, foreign investment is part of development, and development must be measured by ethics, as Amartya Sen shows, and by the improvements in freedoms and rights that it brings to developing countries.

\section{Planteamientos introductorios.}

Los Derechos Humanos y la apreciación ética de la conducta empresarial

Una reflexión acerca de la ética empresarial y la inversión extranjera puede abordarse desde diversos puntos de vista. En este documento se parte de la base de que la apreciación ética de la conducta de un inversionista extranjero es posible y pertinente, como lo es en general respecto de situaciones

\footnotetext{
${ }^{1}$ Ponencia presentada en el Segundo Foro de Derechos Humanos e Inversión Ética en Colombia, patrocinado por la Embajada de Canadá, la Cámara de Comercio ColomboCanadiense y la Pontificia Universidad Javeriana. Bogotá, 19 de febrero de 2002.
} 
jurídicas, económicas y políticas; y de que para tal propósito los derechos humanos cumplen una función referencial o indicativa que permite ponderar diferentes posturas éticas frente a una misma conducta en particular.

Aunque existen conocidas discusiones acerca de la noción de derechos humanos y de su interpretación y aplicación, máxime si se trata de su utilización en el contexto de una argumentación ética y moral y no jurídica; y aunque es claro que el estatuto mismo de la reflexión ética está abierto a un permanente debate, tales cuestiones no se examinan en este momento. De acuerdo con una reflexión jurídica de Otfried Hoffe, que aquí se toma en un sentido normativo más amplio, de manera que cobije el juicio ético y moral, se considera que:

con la ayuda de la idea de los derechos humanos, pero también con la ayuda de reflexiones teórico - institucionales y otras, es posible fundamentar principios normativos rectores para la justicia económica. Pero estos principios ordenan inmediatamente sólo en una parte reducida un determinado hacer y omitir(...).Son, por una parte, normas básicas de acuerdo con las cuales han de ser percibidas, juzgadas, esbozadas y establecidas las correspondientes relaciones económicas. Por otra parte, no indican cómo ha de llevarse a cabo la realización concreta(...)Por ello es necesario elaborar los principios normativos rectores específicamente para cada ámbito y situación y mediar entre ellos, como así también con las exigencias funcionales del respectivo ámbito concreto².

La tesis que se propone en este escrito consiste en que la legitimidad del aprovechamiento de las oportunidades de negocio que ofrecen los países pobres a los inversionistas de los países ricos, no depende ni única ni principalmente del cumplimiento de las leyes del país receptor de la inversión; y que al ser insuficiente la valoración jurídica de la conducta del inversionista, es posible y deseable formular juicios acerca de la rectitud o incorrección ética de comportamientos empresariales específicos. Como lo ha señalado en nuestro medio Guillermo Hoyos Vásquez, frente a las preguntas centrales de ética empresarial, «no bastaría con responder eufemísticamente con presupuestos sociales para las empresas, que sólo respondieran a expectativas de buen manejo y de gestión empresarial dentro de los límites de lo legal» ${ }^{3}$.

\footnotetext{
${ }^{2}$ Hoffe, Otfried. Estudios sobre Teoría del Derecho y la Justicia, trad. J. Seña, Ed. Fontamara, México,2 2a. 1997, p.58.

${ }^{3}$ Hoyos Vásquez, Guillermo «Epílogo», en Cortina Adela, Conill Jesús, Democracia participativa y sociedad civil. Una ética empresarial, Fundación Social, Siglo del Hombre, Bogotá, 1998, p. 175.
} 
Aquí no se pretende sustituir la norma jurídica, sino destacar la insuficiencia de la sujeción a la misma y proponer criterios de legitimación ética con apoyo en las razones que suministran los derechos humanos en el plano de una argumentación o discurso racional entre los posibles afectados por una determinada conducta empresarial, en especial cuando dichos derechos no han sido objeto de desarrollos legales en determinadas materias económicas.

Para ello, el punto de referencia básico es el propio de una comunidad respetuosa de los derechos humanos, respeto con base en el cual cualquier comportamiento empresarial legal, no obstante su legalidad, puede ser revisable desde un punto de vista jurídico, específicamente constitucional, en el país receptor de la inversión. No es ése el punto que interesa ahora, sino plantear cómo ese respeto a los derechos humanos también puede servir de guía principal para la argumentación o uso práctico de la razón de la cual depende la apreciación de dicho comportamiento desde un punto de vista ético. Y ello a pesar, o mejor, precisamente ante la inexistencia de una solidaridad global que responda a una dimensión ética y política común ${ }^{4}$ y que permita entablar con base en ella compromisos a favor de un orden económico justo ${ }^{5}$, pues, tal y como lo expresa Jûrgen Habermas:

Mientras que la solidaridad de los ciudadanos de un Estado está arraigada en una particular identidad colectiva, la solidaridad cosmopolita debe apoyarse exclusivamente en el universalismo moral expresado en los Derechos Humanos ${ }^{6}$.

\section{El contexto propio del punto de vista del país receptor}

Aquí no se examina la cuestión a partir de las expectativas éticas legítimas de un inversionista extranjero acerca de la conducta de los ciudadanos y autoridades públicas del país receptor de la inversión. La óptica escogida corresponde a la del ciudadano de un país receptor teniendo en cuenta el caso específico de Colombia, en el cual resultan relevantes algunas circunstancias, a saber: (a) la pobreza que afecta a gran parte de nuestra población, (b) una altísima criminalidad, en la que el hurto calificado y el homicidio son, respectivamente, el primer y tercer delito de mayor ocurrencia ${ }^{7}$, el secuestro extorsivo y los atentados terroristas contra la infraestructura pública que se han convertido en amenazas particularmente

\footnotetext{
${ }^{4}$ Habermas, Jürgen, La Constelación Postnacional- Ensayos Políticos, trad. P. Fabra, Ed. Paidós, Barcelona, 2000, p. 141

${ }^{5}$ Küng, Hans. Una Ética Mundial para la Economía y la Política, trad. G. Canal, Ed. Trotta, Madrid, 1999, p. 223

${ }^{6}$ Habermas, Jürgen, ob.cit. p. 141

${ }^{7}$ Fiscalía General de la Nación, Informe de Gestión del Fiscal Alfonso Gómez Méndez, 1997-2001, Bogotá, 2001, p.19
} 
nocivas en materia de inversión; (c) el haber sido considerado en 1996 por Transparencia Internacional, entre 54 países, como el décimo tercero de la lista de los más corruptos ${ }^{8}$. Tales situaciones locales deben ser puestas en el contexto de la liberalización de la actividad económica transnacional sin soslayar los enormes contrastes existentes entre pobres y ricos.

\section{La regla de apreciación propuesta.}

En este orden de ideas, se plantea aquí que la conducta de un inversionista extranjero debe ajustarse al criterio de corrección que sea más exigente, entre la ética del país del inversionista y la del país receptor de la inversión. Esta versión del sensato principio según el cual «no hagas a otros lo que no te gusta que te hagan a ti», se aparta de la máxima oportunista según la cual « a donde fueres, haz lo que vieres»; y suministra una regla de apreciación utilizable frente a hipótesis concretas en las cuales una misma conducta sea ponderada en forma distinta de acuerdo con los estándares éticos del inversionista y con los del receptor, cualquiera que sea su justificación o fundamentación en la comunidad respectiva, examen en el cual el contraste entre ambos patrones de comportamiento se hace a la luz de juicios y argumentos racionales propios de una comunidad respetuosa de los derechos humanos.

La aplicación de esta regla de «máximos relativos» supone establecer que en cada caso concreto la diferencia entre ambas apreciaciones sea materialmente relevante desde el punto de vista del derecho o derechos humanos involucrados. Implica, además, que el juicio de reproche o corrección de la conducta de un inversionista extranjero por parte de los nacionales del país receptor no puede formularse - ni siquiera con base en los estándares éticos del país del inversionista - si el comportamiento de los empresarios locales merece el mismo o peores reproches; al fin y al cabo, ya desde la Biblia se ha advertido cómo no puede hablarse de la paja en el ojo ajeno sin reparar en la viga que se tiene en el propio.

\section{Insuficiencia de la valoración jurídica y pertinencia de la apreciación ética}

Los juicios éticos en materia empresarial no sólo son posibles, sino pertinentes, porque, como lo han resaltado, entre otros, Amartya Sen y Adela Cortina, ningún sistema económico, incluyendo el capitalismo, puede subsistir sin un adecuado sistema de valores, cuyo papel en la motivación de los

\footnotetext{
${ }^{8}$ Moody Stuart, George, Feature Service, Página Web del Center For International Private Enterprise.
} 
agentes económicos es relevante ${ }^{9}$. Por esa razón, en la base de legitimación de las empresas el soporte jurídico de la libertad de iniciativa económica de los empresarios se amalgama con las expectativas éticas de la sociedad, de manera que tales normativas están llamadas a reforzarse mutuamente, sin que el déficit coactivo de la ética y de la moral impida criticar desde esa perspectiva las conductas que se ajustan a la ley. Al llevar a cabo esa valoración se apela a pautas de comportamiento compartidas y construidas por los empresarios, que responden a las siguientes características: (a) son respuesta a exigencias y expectativas sociales mínimas no reguladas que involucran la legitimidad de la actividad empresarial más allá de su legalidad, (b) tienen su origen en la moral social y no en la percepción o intuición moral particular, (c) son indispensables en la construcción de la confianza necesaria para la creación y desenvolvimiento de relaciones jurídicas, en especial las de carácter contractual.

Sobre los empresarios que compiten por un mercado, cuya conducta se hace más visible y más sensible en la sociedad contemporánea, es cada vez más intensa la presión que ejercen las expectativas éticas de la sociedad civil, de su clientela potencial e inclusive, de sus propios funcionarios y empleados. Más allá del deseo de ser percibidos favorablemente por la comunidad - presente en las donaciones y en el apoyo empresarial a toda suerte de causas «nobles», con o sin beneficios fiscales- o del cálculo de las ventajas comerciales de una «imagen» ética, los propios empresarios emprenden iniciativas concordantes con tales expectativas, aplicándose a sí mismos estándares adicionales a los puramente legales. Se pone así de relieve que el sujeto éticamente responsable es el ser humano concreto, extranjero o nacional, que recibe dinero a diversos títulos (dividendos, salarios, honorarios, comisiones, etc.) proveniente de ganancias obtenidas de conductas susceptibles de una apreciación ética; no lo son ni poderosas corporaciones transnacionales ni fantasmas jurídicamente engendrados en los paraísos fiscales y bancarios.

Un ejemplo en esta materia, ya citado en otra oportunidad y que conserva su actualidad, lo constituye la política de la British Petroleum, corporación distinguida en 1999 por las Naciones Unidas con el premio al liderazgo individual en medio ambiente, en relación con las emisiones de CO2; sir John Browne, su director ejecutivo, ha dicho al respecto:

Las personas que trabajan en BP son ciertamente personas de negocios, pero también son personas de creencias y convicciones(...) individuos preocupados por la calidad de vida para ellos y sus niños.

\footnotetext{
${ }^{9}$ Sen, Amartya, Desarrollo y Libertad, trad. E. Rabasco y L. Toharia, , Ed. Planeta, Bogotá, 2000, p.334. Cortina, Adela, Ética de la Empresa, Claves para una nueva cultura empresarial, Ed. Tecnos, Madrid, 1998, p. 64.
} 
Cuando pasan por la puerta a su trabajo cada mañana, no dejan atrás sus convicciones y su sentido de responsabilidad. Y lo mismo aplica para nuestros consumidores. Su elección determina nuestro éxito como compañía. Y ellos tienen creencias y convicciones (...) el ambiente global es un tema que nos concierne a todos en nuestros varios roles y capacidades. Primero monitoreamos y controlamos nuestro propio control de emisiones de dióxido de carbono (...) Ninguna legislación nos ha obligado a dar este paso; lo hacemos porque creemos que es lo correcto ${ }^{10}$.

Y ha insistido en que «no se puede dirigir una compañía sobre la base de que solamente se hace lo que la ley demanda (...) Nosotros usamos el cumplimiento de la ley como mínimo y vamos más allá de eso» ${ }^{11}$

\section{La regla de apreciación en función de los estándares éticos del país del inversionista, en el contexto de la relación entre países ricos y pobres.}

La pertinencia de una regla que permita reprochar éticamente al inversionista extranjero en el país receptor de la inversión una conducta que sería reprochable en su país, se pone de manifiesto en tres ejemplos de actualidad: la corrupción, las excepciones a los derechos de patente y su relación con los precios de los medicamentos genéricos, y el trabajo infantil.

1. Ya se mencionó la lista de países más corruptos elaborada por Transparencia Internacional, que es encabezada por países pobres, como lo confirma el primer lugar en que en ella se sitúa a Nigeria. Pues bien, si alguien se tomara el trabajo de elaborar una lista de los países más corruptores, podría pensarse en que, correlativamente, la misma estaría encabezada por países de los más ricos. Probablemente sí, porque la sabiduría popular, apoyada por sor Juana Inés de la Cruz y el derecho penal, tienen bien averiguado que tanto la prostitución como el soborno tienen dos caras. Cuando se repara en el hecho elemental de que el tráfico de «blancas», de trigueñas y morenas suele hacerse desde países pobres «exportadores» hacia países ricos «importadores», y no al revés, se confirma la idea de que "quien paga por pecar" algo tiene que ver con el problema.

Sin embargo, sólo desde hace poco tiempo en los países que no se encuentran en la lista de los países más corruptos se comienza a reaccionar en contra de

\footnotetext{
${ }^{10}$ Browne, John, «Climate Change Speech», Stanford, Mayo 19 de 1997,

${ }^{11}$ Browne, John. Citado en Kluger Jeffrey. «Special Report. Global Warming. A climate of dispair» en Time, Edición Latinoamericana. Abril 10, 2001, p. 26
} 
las conductas reprochables de sus empresarios en el exterior, de manera que, por ejemplo, los sobornos pagados a extranjeros con causa en negocios celebrados fuera de sus fronteras, en vez de ser favorecidos cínicamente como gastos deducibles de impuestos, reciban el mismo tratamiento criminal que se adecua al reproche ético que merecen si se soborna o se intenta sobornar a una autoridad del propio país. Hay una reciente profusión de acuerdos internacionales en materia de corrupción, entre los cuales deben destacarse la Convención de las Naciones Unidas contra el Crimen Transnacional, contenida en la resolución 55/25 del 15 de noviembre del 2000, que, entre otras cosas busca la criminalización tanto de los funcionarios públicos corruptos como de sus corruptores; la Convención de la OECD ( Organización para la Cooperación Económica y el Desarrollo) para combatir el soborno a los funcionarios públicos en las transacciones internacionales de negocios, que entró a regir en 1999, y en cuyo marco se pretende incluir a funcionarios públicos de gobiernos que no forman parte de la convención; y la Convención Interamericana contra la Corrupción, expedida por la Organización de Estados Americanos (OEA) que entró a regir en 1997, que busca promover, facilitar y regular la cooperación entre los Estados miembros para prevenir, detectar, erradicar y castigar la corrupción.

En el plano de las legislaciones internas, en cambio, resulta excepcional una previsión expresa como la de la ley estadounidense de Prácticas Corruptas en el Extranjero de 1977 (Foreign Corruption Practices Act), que establece que los directores de empresas estadounidenses que sobornen, directa o indirectamente, a funcionarios públicos o a políticos en el exterior, serán tan culpables como si hubieran sobornado a un ciudadano estadounidense. Es en ausencia de normas legales como ésta cuando el reproche fundado en los estándares éticos aplicables en el país inversionista resulta adecuado dentro de la construcción de una ética empresarial aplicable a la inversión extranjera.

2. El asunto de los medicamentos genéricos, su amparo con los correspondientes derechos de patente y sus precios de comercialización, ofrece otro interesante ejemplo de por qué la formulación sincera y consistente de una ética empresarial en el campo internacional es tan difícil. La autorización de la producción de medicamentos genéricos utilizables por los enfermos de sida, con base en una regla de la Organización Mundial del Comercio (OMC) aplicable en casos de emergencia nacional, que prevé licencias compulsivas que constituyen una excepción frente al monopolio temporal derivado de los derechos de patente, dio lugar, en el caso de Sudáfrica - país que ocupa el primer lugar en el mundo en la lista de la población infectada por dicha enfermedad - a la iniciación y posterior retiro de un litigio contra ese país, promovido por importantes corporaciones transnacionales de la industria farmacéutica. En el caso de Brasil, la fabricación a partir de 1997 de drogas utilizables por los enfermos de sida - que se 
calcula ascienden en ese país a 500.000- bajo el régimen de la licencia compulsiva - permitió una disminución en el precio en un promedio del $79 \%{ }^{12}$ y dio lugar, en el marco de un exitoso programa de salud pública, tanto a una reducción del $40 \%$ en el número de muertes vinculadas a esa enfermedad como a una queja elevada por los Estados Unidos ante la $\mathrm{OMC}$ en febrero del año pasado, con el objeto de revisar si dicha producción de genéricos de medicamentos con patentes estadounidenses se ajusta o no a las reglas de la $\mathrm{OMC}^{13}$.

Los beneficiarios de las patentes, entre otras cosas, señalan la indiscutible importancia de los derechos de patente como estímulo para la creatividad y el desarrollo, la magnitud de los recursos que reclama la investigación en este campo, así como la necesidad de preservar los derechos contractuales de los accionistas ante quienes rinden cuentas los administradores de todas las sociedades comerciales. Estos importantes argumentos, tan sensibles desde el punto de vista de los derechos de los inversionistas y de la estabilidad de las reglas del juego que les son aplicables en los países receptores de sus inversiones, son pertinentes en el caso de la producción y comercialización de cualquier medicamento.

No obstante, parece que su discusión y descarte frente a otros argumentos fue más rápida y sencilla en el caso específico del precio del Cipro, antibiótico utilizado para el tratamiento de pacientes infectados con ántrax, y en relación con cuya disminución la farmacéutica productora y el Departamento de Salud y Servicios Humanos del gobierno estadounidense suscribieron un acuerdo para mantener la exclusividad de la patente y disminuir el precio por píldora de US $\$ 1.77$ a US\$0.95. Hay que destacar que según las declaraciones de un alto funcionario de la farmacéutica, «Bayer se siente solidaria con Estados Unidos y apoya totalmente su lucha contra el bioterrorismo» ${ }^{14}$. Tan sólo cinco días después del anuncio de dicho convenio, que incluía la donación de dos millones de unidades del medicamento, el Centro para el Control y la Prevención de las Enfermedades (CDC) de los Estados Unidos, anunció la sustitución del Cipro por un genérico, la doxiciclina, de manera que el gobierno no tendría que pagar los cien millones de dólares derivados del acuerdo firmado con Bayer y que suministraría al Departamento de Salud cerca de 95 millones de tabletas. La prensa divulgó unas declaraciones de la portavoz de la CDC, quien explicaba el cambio en la situación desde un punto de vista científico, ya que «nuestras recomendaciones para tratar esta enfermedad cambian al tiempo que tenemos nuevas informaciones y mejor conocimiento de esta contaminación», y se dieron a conocer también las quejas de una empleada del servicio

\footnotetext{
${ }^{12}$ Rosenberg, Tina «Patents laws are malleable. Patients are educable. Drug companies are vincible. The world's AIDS crisis is solvable», en The New York Times Magazine, Nueva York, enero 28 de 2001, pp. 26 y ss.

13 «La Batalla de Brasil por los Genéricos», en Portafolio, Bogotá, abril 23 de 2001, p.28.

${ }^{14}$ Bay News, Página Web. Bayer Farmacéutica., Noticias Octubre 2001. Chile. 2001
} 
postal americano, quien apuntaba: «espero que no tomen esta decisión de cambiar de medicamentos porque es más barato» ${ }^{15}$

La existencia de un doble estándar de esta clase resulta inconsistente frente al respeto a la dignidad humana del paciente de una enfermedad mortal, circunstancia cuya apreciación desde el punto de vista de los derechos humanos impide distinguir entre la causa de la infección, la nacionalidad, raza o color del enfermo.

3. La frontera entre la consideración de la mano de obra como un factor de producción barato y, como tal, favorable para la competencia mundial, y la explotación del trabajo infantil, no depende solamente del régimen legal local. La situación en algunos países es tal que la alternativa real al trabajo infantil usado en algunas partes del mundo para la manufactura y producción de artículos comercializados por corporaciones extranjeras se materializa en una absoluta falta de oportunidades, que precipita a los niños hacia la delincuencia, la prostitución o los deja en garras de peores formas de explotación laboral por parte de empresarios locales. Entonces, el simple y pragmático argumento de la preferencia del mal menor es útil para criticar las consecuencias previsibles de reacciones radicales y simplemente represivas. En este orden de ideas, son claras las ventajas que reporta el apoyo por parte de la comunidad internacional a políticas como la del Programa Internacional de Erradicación del Trabajo Infantil orientado por la Organización Internacional del Trabajo (OIT) ${ }^{16}$.

Pero abstracción hecha de tales programas, y para lo que aquí interesa, la regla de apreciación propuesta exige respeto del ser humano, particularmente del niño, cuya protección es objeto contemporáneamente de numerosas declaraciones internacionales, que obedecen a principios que se supone forman parte de los estándares éticos del país del inversionista. Esta es la razón por la cual, de acuerdo con dicha regla, no sería éticamente aceptable que dicho inversionista extranjero -cualquiera que fuera su motivación, v. gr., la búsqueda de un competitivo ahorro de costos en la mano de obra, o el laudable propósito hipotético de generar alternativas frente a la delincuencia - usara el trabajo infantil en el país receptor, con sujeción a la legislación interna de éste aunque esta forma fuese inaceptable dentro de su propio país. El principio aplicable le exigiría no hacerle a los niños de otros lo que no le gustaría que le hicieran a los propios, inclusive si existe una alta probabilidad de que alguien los trate peor.

\footnotetext{
15 «Un genérico sustituye al Cipro» en Página Web El mundo, Madrid, 29 de octubre de 2001, ${ }^{16}$ Bhagwati, Jagdish, «Coping with Antiglobalization», en Foreign Affairs, Nueva York, enerofebrero 2002, p. 6
} 


\section{La autoridad moral del país receptor de la inversión para formular repro- ches éticos al inversionista extranjero.}

Una interesante y constante característica histórica de la formación del derecho comercial, que desde sus orígenes ha tenido una clara vocación internacional, radica en la necesidad de ofrecer a los extranjeros, además de confianza en la estabilidad de las reglas del juego, igualdad de trato frente a los comerciantes locales. Por esto ha dicho Berman que un tratado suscrito en el siglo XII, entre el rey Enrique II de Inglaterra y la ciudad de Colonia, que aseguraba a los comerciantes de esa ciudad un trato no menos favorable que el que recibían los mercaderes ingleses, es probablemente « el más antiguo ejemplo que sobrevive de la cláusula de tratamiento nacional y un precursor de la cláusula de la nación más favorecida de los tratados comerciales modernos ${ }^{17}$.

Esta reciprocidad de derechos, indispensable en las relaciones jurídicas privadas de carácter comercial, implica que en atención a las expectativas en que se funda la apreciación moral, al igual que por razones de sinceridad y consistencia, el juicio de reproche o corrección de la conducta de un inversionista extranjero por parte de los nacionales del país receptor depende en la práctica de si éstos tienen autoridad para formularlo. Y dicha autoridad a su vez depende de los estándares éticos que éstos aplican a su propio comportamiento. Hay entonces que preguntarse con franqueza, cuáles son los estándares éticos efectivamente imperantes en nuestra actividad empresarial, sin perder de vista que forman parte del conjunto normativo que regula en nuestro país la actividad económica y de la situación general en materia de derechos humanos.

Esta inquietud no desconoce que la preocupación ética ha sido explícita en nuestro medio empresarial, como lo pone de relieve la instalación de la Asamblea General Ordinaria de Afiliados de la Asociación Nacional de Industriales 200 (ANDI) de 1999, en la cual se señalaron, en su orden, la ética, la competitividad y la eficiencia como imperativos actuales para la conducta de los empresarios colombianos $^{18}$. Pero no puede ignorarse que cuando se formulan reparos frente a un inversionista extranjero en un caso específico, generalmente los mismos suelen ser igualmente aplicables a empresarios colombianos competidores en el mismo sector. Más en el fondo de la cuestión, hay que reconocer que en una economía con tan altos grados de concentración de la propiedad y del ingreso, y con tasas de desempleo tan elevadas, todos los protagonistas de la actividad económica local enfrentan dificultades para quejarse con autoridad de los im-

\footnotetext{
${ }^{17}$ Berman, Harold J. Law and Revolution - The Formation of the Western Legal Tradition, Harvard University Press, Cambridge, 1983, p. 344

${ }^{18}$ Discurso del presidente de su junta directiva, Nicanor Restrepo, pronunciado en Medellín el 12 de agosto de 1999.
} 
pactos negativos de la liberalización del comercio. Los empresarios, en la medida en que no han podido o no han querido liderar en nuestras instituciones políticas y económicas una actividad empresarial interna realmente competitiva, que es la mejor garantía de calidad y buen precio para los consumidores. Los sindicatos, porque aunque aparentemente no representan siquiera a un número de trabajadores igual a la mitad de los ciudadanos desempleados ${ }^{19}$, en nombre de la defensa dogmática de ciertos derechos de los trabajadores sindicalizados dificultan la creación de nuevos empleos por parte de empresarios locales y extranjeros. Los propios consumidores tampoco resultamos bien librados en cuanto a autoridad se refiere, si, por ejemplo, se repara en el inveterado hábito nacional de adquirir bienes de contrabando, origen de los célebres «sanandresitos», que sólo recientemente han comenzado a decaer, si bien es justo recordar cómo productores y proveedores extranjeros importantes no son del todo ajenos a esa distribución ilegal, sin que las acciones legales al respecto sean eficaces ${ }^{20}$. Y el Estado, cuando actúa como autoridad pública o cuando toma el papel de empresario - además de los reparos derivados de la corrupción, antes de plantear reclamos éticos ante terceros - debe cumplir con sus cometidos constitucionales fundamentales.

Pero el irrespeto a la vida humana y la indolencia frente al dolor ajeno que se expresan en el alto índice de homicidios y en el secuestro, son las muestras de falta de solidaridad que en la práctica minan más que cualquier otra cosa nuestra autoridad para cualquier pronunciamiento ético frente a cualquier extranjero. Y eso que ahora, como consecuencia de la generalización de la crisis económica, el secuestro y la extorsión se «democratizaron», de modo que cualquier colombiano con carro es secuestrable. Esta amenaza ha afectado considerablemente la conservación y la generación de empleos, por lo cual la ciudadanía ha comenzado a dejar atrás la resentida e inmoral apreciación del problema como algo que no le importaba a la mayoría porque sólo afectaba a la minoría de ricos, tanto nacionales como extranjeros, incluyendo entre estos últimos a funcionarios de las compañías extranjeras que invierten en Colombia. Uno de ellos, de nacionalidad japonesa, fue secuestrado en Bogotá hace ya algunos años por agentes de la policía a pocos metros de la carrera séptima, aberración que dio lugar al inicio de una importante depuración en esa fuerza pública .

\footnotetext{
${ }^{19}$ Véase Marulanda Gómez, Eugenio, Colombia: País de Paros, Documentos de Coyuntura, no. 1. Confecámaras, Bogotá, 1999, pp. 13-16. Se calcula que el número de los trabajadores sindicalizados (CUT, CGTD, CTC e independientes) no llega al millón de personas.

${ }^{20}$ Como lo comprueba el fracaso de la demanda instaurada por todos los departamentos colombianos y la ciudad de Bogotá contra Philip Morris y R.J. Reynolds, véase «Departamentos fallan en demanda a Tabacaleras» en El tiempo, Bogotá, febrero 20 de 2002.p.8, noticia publicada al día siguiente de la presentación de esta ponencia.
} 
Piénsese en el caso del trabajo infantil, hace ya varios años dramáticamente sintetizado en Chircales, la película de Rodríguez y Silva, para no hablar del reclutamiento de niños con ocasión del conflicto armado, situación de la cual nadie puede pretender responsabilizar a ningún empresario extranjero, con excepción de la responsabilidad que le quepa compartir en ello a los traficantes y productores extranjeros de armas y a los eslabones extranjeros del negocio de la droga, tales como productores de acetona y banqueros.

Como fue puesto de relieve por Hans Küng, las transacciones financieras internacionales dependen de la observancia de dos principios éticos inmemoriales y básicos: «no mentir»y «no robar» ${ }^{21}$. Por desgracia, el estándar ético de nuestros empresarios en cuestiones tales como la lealtad en el cumplimiento de los contratos o la confiabilidad de su información financiera y contable, no permite alzar la voz frente a comportamientos reprochables equivalentes de acreedores o deudores extranjeros; aunque debe advertirse que frente a escándalos de la magnitud de la bancarrota de la empresa Enron se quedan cortas las malas artes de nuestros caballeros de industria, cuyo número disminuye por su traslado a los países donde se encuentran sus cuentas personales, y no porque exista una sanción moral interna al respecto. El éxito local de dos excelsos productos de exportación, las telenovelas «Café» y «Betty la Fea», además del talento de sus actores y guionistas, también obedece a que el parecido entre las trapisondas de «Café Export» y «Ecomoda» y la realidad no es simple coincidencia; y la reacción general de los televidentes al respecto mostraba ante ellas un alto grado de tolerancia o indiferencia social, que contrasta con el excesivo celo colectivo empeñado en la protección jurídica de la confidencialidad del pasado comercial de los deudores morosos. ${ }^{22}$

La existencia de un buen gobierno corporativo, afianzado por códigos de conducta, que en ciertos casos son exigidos legalmente, como ocurre en el caso de las bolsas de valores, los comisionistas de bolsa y las sociedades que aspiran a ser objeto de inversión de las sociedades administradoras de fondos de pensiones, es indispensable para promover un mercado de capitales, escenario natural para impor-

${ }^{21}$ Küng, Hans «Ethical Standards for International Financial Transactions», presentado en 38th International Federation of Stock Exchanges, FIBV, General Assembly, october 1998, Kuala Lampur, pp. 7, 8. Esta intervención fue dada a conocer en nuestro medio en la septuagésima conmemoración de la fundación de la desaparecida Bolsa de Bogotá por su Presidente y actual Presidente de la Bolsa de Colombia, Augusto Acosta

${ }^{22}$ Además de los fallos judiciales basados en argumentos de tipo constitucional, en el artículo 19 de la ley 716 del 2001 se dispuso que «Las personas que dentro del año siguiente a la vigencia de la presente Ley se pongan al día en obligaciones por cuya causa hubieren sido reportadas a los bancos de datos de que trata este artículo tendrán un alivio consistente en la caducidad inmediata de la información negativa histórica, sin importar el monto de la obligación e independientemente de si el pago se produce judicial o extrajudicialmente. La Defensoría del Pueblo velará por el cumplimiento de esta norma». 
tantes inversiones del exterior. En tiempos de crisis económica, esa clase de códigos de comportamiento empresarial son necesarios también en las empresas beneficiarias del crédito, pues es a través del mismo como la mayoría de ellas obtienen recursos de capital. Ese era el propósito inspirador de la exigencia legal de la adopción de códigos de conducta empresarial por parte de las empresas que celebren acuerdos de reestructuración en los términos de la ley 550 de 1999, de manera que se establecieran:

reglas de comportamiento para la administración de las empresas que correspondan a estándares mínimos constitutivos de una ética empresarial cuya construcción y apropiación colectiva es indispensable para la celebración y el cumplimiento de acuerdos de reactivación ${ }^{23}$.

Sin embargo, la experiencia en ese campo muestra que tales códigos en muchos casos se limitan a ser formatos carentes de contenido concreto, y hay que suponer que puesto que la ley no puede impedirlo, en la práctica se promueven y negocian acuerdos de reestructuración exclusivamente inspirados en el propósito de escudarse frente a los acreedores o de imponerles esperas o rebajas, sin analizar con la mayor objetividad y buena fe posibles la viabilidad de la empresa. Actitud que es de vieja data en nuestro medio, pues es la misma «cultura de no pago»-como se le dice ahora- que ha inspirado muchos concordatos tramitados y celebrados legalmente, y que no permite quejarse con autoridad de los frecuentes abusos de los acreedores, tanto nacionales como extranjeros, que se consuman también dentro de la ancha manga de la ley.

\section{Los derechos humanos y una actitud ética hacia la pobreza.}

Ya se ha dicho que los derechos humanos, cuya formulación y respaldo coactivo es cada vez más de tipo jurídico, se encuentran en la base de esas expectativas mínimas de la comunidad que dan origen a la ética empresarial.

Y ello porque éstos no remiten únicamente a exigencias de carácter político; y porque al igual que en el caso del poder estatal, el ejercicio del poder empresarial también es susceptible de una apreciación crítica en función de su concordancia con los derechos humanos. De ahí que la formulación de proyectos de tratados, de leyes uniformes y de guías legislativas en cuestiones propias del

\footnotetext{
${ }^{23}$ Exposición de Motivos. Proyecto de ley de Intervención Económica, rad. 14599, Cámara de representantes, octubre 20 de 1999, presentado por los ministros Juan Camilo Restrepo S. y Jaime Alberto Cabal S., p.6
} 
derecho mercantil internacional por parte de la Comisión de las Naciones Unidas para el Derecho Comercial Internacional (CNUDMI), se inspire también en la paz y el desarrollo, es decir, en los objetivos fundamentales de dicha organización ${ }^{24}$.

Hay que reiterar entonces la relación que existe entre el desarrollo y los derechos humanos. Es a partir del respeto a los derechos humanos, y no sólo con base en el cálculo de la utilidad económica que reporta una inversión extranjera, tanto para el inversionista ( dividendos, derechos de licencia, márgenes derivados de la reducción de costos de mano de obra, etc.) como para el país receptor ( nuevos empleos, obtención de capital, adquisición de tecnología, inserción en la economía global, etc. ) como se aprecia el importante papel capaz de cumplir la inversión extranjera al suministrar recursos y oportunidades indispensables para el desarrollo de los ciudadanos de los países pobres.

El examen de la ética empresarial en materia de inversión extranjera debe ponerse en el contexto mundial de contraste entre países pobres y ricos. Desde un punto de vista ético no es aceptable que la liberalización del comercio mundial, es decir, la expansión de la libertad de iniciativa económica privada y de contratación en el campo internacional, se haga a expensas de la libertad de los ciudadanos de los países pobres. Si se acepta que la liberalización del comercio es favorable para el desarrollo de los países pobres, es necesario recordar que por desarrollo hay que entender, de acuerdo con Amartya Sen, «..el proceso de expansión de las libertades reales de que disfrutan los individuos» ${ }^{25}$, de manera que si, como él mismo lo señala, la pobreza es una privación radical de la libertad económica, que puede a su vez fomentar la falta de libertad política y social. la legitimidad de la ganancia del inversionista extranjero, desde un punto de vista ético, exige que ésta no se obtenga a expensas de la pobreza del país receptor, evaluación compleja y que en cada caso debe hacerse de manera prudencial, recurriendo, más allá de los marcos legales de negociación local o internacional, a la piedra de toque de los derechos humanos.

Esa apreciación, que es de carácter normativo, exige la consideración de los derechos del inversionista extranjero a partir de una perspectiva que no se agota en su valoración jurídica, como lo pone de relieve el momento en que se

\footnotetext{
${ }^{24}$ Corell, Hans, Consejero Legal de la ONU,documento UNIS/L/86, julio 9 del 2001, pp. 1-2. Como lo pone de relieve la declaración conjunta del 5 de julio de 1999 del secretario general de la ONU y del presidente de la Cámara de Comercio Internacional de París, mencionada por el Subsecretario General de Asuntos Legales de la ONU en su mensaje a la CNUDMI, con ocasión de su sesión del año pasado.

${ }^{25}$ Sen, Amartya. Ob. Cit. p. 19
} 
sopesan frente al denominado «derecho a no sufrir hambre», prerrogativa que se postula hoy desde un punto de vista ético; de ahí que Amartya Sen señale que la afirmación de este derecho se lleva a cabo en primera instancia como:

una exigencia moral de algo que tendría que ser valorado y hacia lo que tendríamos que hacer que apuntaran las estructuras institucionales y que se debería tratar de garantizar en lo posible. Puede ser expresado en los términos de la categoría de Ronald Dworkin de «derechos básicos», derechos que proveen de una justificación para decisiones políticas por parte de una sociedad en abstracto. Esta interpretación sirve para una mentalidad de cambio de las estructuras institucionales existentes y de organización política ${ }^{26}$.

${ }^{26}$ Sen, Amartya, «Propiedad y Hambre», en Precedente-Anuario Jurídico, Centro de Investigaciones Sociojurídicas de la Facultad de Derecho y Humanidades de la Universidad Icesi, Cali, 2001, p. 104 